\title{
Distance and Trust: An Examination of the Two Opposing Factors Impacting Adoption of Postal Voting Among Citizens Living Abroad
}

\author{
Miroslav Nemčok $^{1}$ D Johanna Peltoniemi ${ }^{2}$
}

Accepted: 15 April 2021

(c) The Author(s) 2021

\begin{abstract}
Postal voting intends to provide citizens residing abroad with a convenient voting technique to influence political representation in their country of origin. However, its adoption among individuals is dependent on two opposing factors. On the one hand, voting via post helps to overcome the increasing distance between a voter's residency abroad and the nearest polling station organized by a diplomatic mission (mostly at an embassy or a consulate). On the other hand, this way of voting also requires enough trust that the postal service and designated state office will successfully deliver one's vote to the ballot box because the result cannot be effectively verified without violation of the ballot secrecy. We examine the interaction of these two factors in an originally conducted survey among Finnish citizens residing abroad fielded shortly after the 2019 Parliamentary elections- the first occasion after Finland put postal voting into effect. Altogether, 664 respondents responded to all questions required for our specification of binomial logistic regression models controlling for various potential confounders. The results demonstrate that trust in postal voting moderates the impact of distance on one's probability to adopt postal voting. While low-trusting emigrant voters remain largely indifferent regardless of the distance to the nearest polling station, medium-trusting non-resident citizens increasingly mail their ballots when the nearest polling station is more than $100 \mathrm{~km}$ away. High-trusting individuals begin to increasingly do so when they are ten to $30 \mathrm{~km}$ away.
\end{abstract}

Keywords Postal voting · Vote-by-mail · Trust · Distance $\cdot$ Emigrants $\cdot$ Finland Political geography

Miroslav Nemčok

miroslav.nemcok@stv.uio.no

Johanna Peltoniemi

johanna.peltoniemi@helsinki.fi

1 University of Oslo, Postboks 1097, Blindern, 0317 Oslo, Norway

2 University of Helsinki, P.O. Box 9, 00014 Helsinki, Finland 


\section{Introduction ${ }^{1}$}

A growing number of contemporary democracies recognize the increasing intensity of human mobility and aim to provide universal access to electoral participation for their citizens (Beckman, 2012). In fulfilling this goal, countries implement new voting techniques to facilitate the electoral participation of citizens who temporarily or permanently reside abroad (Peltoniemi, 2016a). The real intention motivating this effort seems to be to keep up the interaction between emigrating citizens and the polity of their origin to increase the chances that these individuals will return in the future (Honohan, 2011; Smith, 2003).

Postal voting represents one of these attempts. It allows citizens to apply for a ballot in advance and return it via mail to the state office administering the election (Braun \& Gratschew, 2007). However, this method of electoral participation imposes a dilemma. On the one hand, casting one's ballot via post is a convenient way to reduce the costs of reaching the closest polling station while residing in a foreign country, especially if the nearest diplomatic mission organizing elections is located in a distant city or neighboring country (Qvortrup, 2005). On the other hand, however, postal voting does not allow supervision of one's electoral ballot. Therefore, voters have to trust that their envelopes will successfully pass the significant distance to the ballot box in their home country without being compromised, regardless of the validity of their concerns (Stewart III, 2010). Moreover, the ballot has to arrive on time; otherwise, it is deemed invalid (Foley, 2020). The two bodies of literature studying one of the two above-outlined factors have coexisted without any notable interactions. To the best of our knowledge, this is the first research to bridge the two streams and examine the interaction between distance and trust- the two factors with opposite effects on the individual's decision to vote via post.

To address this objective, we fielded an original survey among Finnish citizens residing abroad shortly after the 2019 Finnish Parliamentary election. This event constituted the first occasion when Finnish voters residing abroad were allowed to cast their electoral ballots also via post-in addition to voting at the polling stations organized by diplomatic missions outside of the country. Because postal voting was still not available within the country, we were able to examine how individuals decide whether to mail in their ballots along a wide range of distances to the nearest polling station (up to $1000 \mathrm{~km}$ ) and depending on their level of trust in postal voting.

Altogether, 664 respondents provided all answers required for the full specification of estimated binomial regression models that examined the two main covariates and controlled for other potential and theoretically relevant confounders. First, we successfully replicate the results reported in the literature regarding the separate effects of the two factors falling under the scope of this study: Growing trust and growing distance increase the probability that voters will adopt postal voting as

\footnotetext{
1 Replication materials (data and code) are available at https://doi.org/10.7910/DVN/TQLKOJ. Due to privacy constraints, the addresses of survey respondents cannot be made publicly available. Please contact the authors if you are particularly interested in this part of the analysis.
} 
their technique of electoral participation. Second, we propose an original theoretical notion that an individual's degree of trust in postal voting moderates the effect of distance on one's probability to cast a ballot via post. Interaction of these two factors in our data provides strong empirical support for such dependence. Distance to the nearest polling station has a negligible effect on the adoption of postal voting among individuals who doubt the integrity of this voting method. Regardless of the distance, the probability that low-trusting citizens residing abroad will mail in their ballot is constantly small (around $5 \%$ or less). In contrast, non-resident voters with high levels of trust are four times more likely (i.e., 20-25\%) to mail in their electoral ballots, even when the nearest polling station is within the range of ten to $30 \mathrm{~km}$. Beyond this mark, the probability that high-trusting individuals will send their ballots via post rapidly increases. Medium-trusting voters follow an analogous trend; however, the likelihood that they will adopt postal voting as their method of electoral participation begins to accelerate quickly as the nearest polling station becomes more than $100 \mathrm{~km}$ away. Until then, the probability is around $10 \%$.

These findings have important implications for electoral authorities in the implementation of voting via post. If authorities wish to universally expand enfranchisement among their non-resident citizens, they need to improve the degree of control that allows voters to check the timely delivery of their ballot into the ballot box without being compromised. Otherwise, the mission cannot be successful because the implementation of postal voting will not be attractive for those with serious concerns about the integrity of the whole procedure, for whatever reason. Besides electoral studies and research of voting behavior, this conclusion also contributes to the field of political geography because it demonstrates that trust in electoral procedures moderates the influence of geographical distance on an individual's decision regarding how to approach electoral participation.

\section{Postal Voting: Theoretical Outline and Main Determinants of Its Adoption}

Since citizens permanently residing abroad (i.e., long-term emigrants) are unlikely to be affected by decisions made by authorities in their home country (Beckman, 2014), many political theorists normatively argue against granting these persons voting rights in their country of origin (e.g., López-Guerra, 2005; Song, 2012). Nevertheless, contemporary democratic systems seem to be proceeding in the opposite direction; an increasing number of countries have acknowledged the intensification of human mobility (Beckman, 2012) and expanded enfranchisement among their emigrant citizens (Peltoniemi, 2016a). This trend has been interpreted as a strategy to stimulate loyalty to the country of origin (Smith, 2003) and keep reasonable prospects of emigrants' return by maintaining a steady connection between them and the polity (Honohan, 2011).

One of these strategies is the implementation of convenient voting methods that facilitate emigrants' electoral participation during the time abroad (Braun \& Gratschew, 2007). Postal voting, standing under the focus of this research, belongs among the convenient voting methods that aim to allow electoral participation of 
voters who are unable to vote directly at the polling station on election day (either due to short-term travel or permanent residency abroad). The procedure consists of several steps. First, the voter has to submit a request to the designated state office, which then dispatches voting materials to the supplied foreign address where the voter completes the electoral procedure and returns the vote via postal service (or by fax, e.g., in Australia and New Zealand under specific circumstances). Apparently, in order to work, this procedure must begin well in advance of the election day (Qvortrup, 2005).

Other distant voting options include voting in person at a designated diplomatic mission (e.g., embassy, consulate), designating a proxy who is then allowed to vote on behalf of a voter at the polling place, and internet voting, which is currently employed country-wide in Estonia, for example.

In the European Union, postal voting (in some form) is implemented by 17 member states. However, the impact of this convenient voting method on electoral participation-whether among emigrants or the countries' whole electorates-finds mixed evidence and hence seems to be dependent on a specific context. For example, the turnout skyrocketed from $4.4 \%$ in 2001 to $38.9 \%$ in 2006 among non-resident Italians when postal voting was available for the first time. However, essentially no difference can be observed in Sweden, where turnout among Swedes living abroad changed from $26.8 \%$ in 1998 to $27.0 \%$ in 2002 with postal voting in place (Peltoniemi, 2018, pp. 130-131). If one aims to tackle the overall impact of postal voting on electoral turnout, findings by Luechinger et al. (2007) from Switzerland suggest that the introduction of this voting technique increased the overall degree of electoral participation by roughly $4.1 \%$. Another Swiss study by Hodler et al. (2015) reported a similar finding - that implementation of postal voting accounts for a 5\% increase in turnout. However, evidence from the US suggests that the boost appears only shortly after implementing postal voting and subsequently deteriorates until it disappears in two to three electoral cycles (Berinsky et al., 2001; Giammo \& Brox, 2010; Gronke \& Miller, 2012).

Previous research has suggested that voting by mail tends to mobilize those who do not vote because of inconvenience rather than convincing non-voters to vote (Southwell \& Burchett, 2000). Thus, since voter facilitation is often introduced to raise turnout among all potential voters, it does not improve typical inequalities in electoral participation (see, e.g., Karp \& Banducci, 2000, p. 235; Southwell, 2010, p. 108). In fact, Wass et al. (2017) have suggested that except for proxy voting, voter facilitation instruments have insignificant main effects, and voter facilitation intensifies differences by activating those who are more active to begin with. Therefore, as voter facilitation has actually increased the socioeconomic bias in turnout, mobilizing groups that were already more active, attempts to make voting more convenient may in fact decrease the socioeconomic representativeness of the electorate, contrary to the original aim (Berinsky, 2005; Berinsky et al., 2001; Bhatti, 2012; Brady \& McNulty, 2011; Karp \& Banducci, 2000; Tokaji \& Colker, 2007).

Nevertheless, postal voting imposes a specific set of constraints when compared to voting in person, especially in the case of voters residing abroad. Since personal voting requires voters to go to a polling place in person, long-term emigrants have to dedicate time and effort to participate in elections. While mailing 
a ballot mitigates part of these expenses, it comes with the risk that one's ballot may be compromised or arrive too late to be counted. Hence, these two forces act against each other, and it remains a question to what degree they cancel each other out. This objective is tackled on the following lines.

\section{Overcoming the Distance: Decreasing the Costs of Voting from Abroad}

When it comes to the costs, voting in person demands significant effort because it requires voters to visit a polling station. In fact, these direct costs related to reaching the polling station have been found to be a stronger determinant of citizens' electoral participation than information/decision costs needed to acquire sufficient information to make a voting decision (Blais et al., 2019). Moreover, the travel expenses and time commitment grow with the increasing distance to the nearest polling station. Therefore, it is hardly surprising that a robust body of literature repeatedly runs into essentially the same conclusion: Increasing distance between one's home and the polling station has a negative impact on a person's likelihood to turn out (Bhatti, 2012; Brady \& McNulty, 2011; Gimpel \& Schuknecht, 2003; Haspel \& Knotts, 2005; Karp \& Banducci, 2000). However, if concurrent voting methods are available, distance to the polling station rapidly increases the chances that voters will employ postal voting or some other absentee and convenient voting methods (Dyck \& Gimpel, 2005; Gronke et al., 2008).

When it comes to voting abroad, direct costs can grow massively because the nearest polling station for in-person voting can be located at an embassy or consulate in a distant city or even in a neighboring country. These constraints constitute a clear factor impacting the emigrants' voting behavior: In a survey conducted among Finnish emigrants, the distance to the nearest polling station was the strongest predictor in their likelihood to turn out (Peltoniemi, 2016b). In response, countries willing to stimulate turnout among more of their citizens residing abroad have implemented various convenient voting techniques, which should decrease the costs associated with the need to reach the nearest polling station in person (Qvortrup, 2005).

However, when it comes to voters' sociodemographic backgrounds, the composition of the electorate remains roughly comparable before and after the implementation of convenient voting techniques. None of the basic individual-level characteristics commonly studied in social sciences (e.g., age, gender, education, income) has been found to be associated with the likelihood to vote by mail (Southwell \& Burchett, 2000) or vote early (Neeley \& Richardson, 2001). Therefore, neither postal voting nor other convenient voting techniques seem to trigger electoral participation among specific social groups.

Following this reasoning, we expect that increasing distance between voter's residency abroad and the nearest polling station increases the likelihood to adopt postal voting (Hypothesis 1). 


\section{Trust: Concerns About the Integrity of Postal Voting}

The problem of convenience voting methods is that all forms, postal voting included, are theoretically open to fraud, and there is no practicable way of preventing it without significant violation of citizens' democratic rights (Birch \& Watt, 2004; Mawrey, 2010). When compared to other democratic procedures, postal voting lacks proper identity-checking procedures comparable to voting in person or electronically (Puiggali \& Morales-Rocha, 2007). This opens the possibility of forged signatures and other personal checks. Already a basic set of information about another person can be sufficient for an identity thief to acquire another person's voting materials and return them as valid votes, which is an issue that must be taken seriously, regardless of its possibility to distort overall electoral results (Gronke et al., 2008).

From voters' perspective, this way of voting requires a substantial amount of trust in the integrity of the whole procedure. Even though it is possible to track their shipment, voters cannot do much about their ballot running late (Foley, 2020). While it is possible to check the delivery of a ballot to the designated state office, no tracking is available to control whether state workers processed the envelope and it was successfully delivered to the ballot box (Stewart III, 2010). Essentially, there is no possible supervision to indicate that the ballot was not compromised somewhere along the way because any convincing solution would necessarily result in violation of ballot secrecy (Braun \& Gratschew, 2007). Therefore, insufficient trust in the integrity of the whole postal voting procedure can prevent citizens from adopting it and thus effectively diminish any positive effects that postal voting can bring to the electoral engagement of citizens residing abroad.

Even though there are very few examples of electoral fraud, and indications that ballot secrecy may be compromised are marginal (Olsen \& Nordhaug, 2012; Qvortrup, 2005), concerns about the integrity of the voting procedure are nevertheless vividly present in the perception of voters (Southwell \& Burchett, 1997) and must be taken into consideration. Lack of trust in the secrecy and security of voting could interfere with the decision of individuals to mail their ballot via post. However, finding the balance may vary across the electorate. For this reason, states should offer several voting methods (such as personal and postal) so voters may individually assess the inconvenience and trust issues and then choose a preferred method on their own (Peltoniemi, 2018).

Following this stream of literature leads us to expect that increasing concerns about the integrity of postal voting decreases the likelihood to adopt postal voting (Hypothesis 2). 


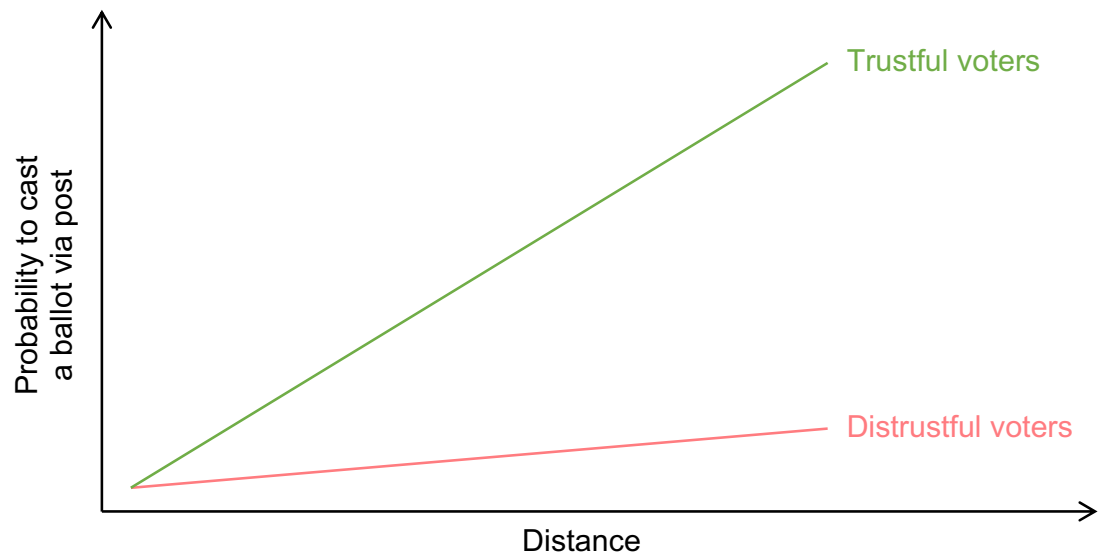

Fig. 1 Moderating effect of trust: Comparing the effect of distance among trustful and distrustful voters (i.e., visual representation of Hypothesis 3)

\section{Trust as a Moderator: Adoption of Postal Voting Among Trustful and Distrustful Citizens}

However, the two factors discussed above-distance and trust-operate in opposite directions. On the one hand, voting via post mitigates the troubles related to the distance between a voter's residency in a foreign country and the nearest polling station (Qvortrup, 2005). Thus, the opportunity to send a ballot via postal service should increase the chances that the voter will turn out to vote. On the other hand, voters will be hesitant to adopt this voting procedure unless they are sufficiently confident about the trustworthiness of postal voting (Southwell \& Burchett, 1997).

Even though a body of research examines each of these factors separately, to the best of our knowledge, no work brings the two factors together and examines their interaction. Following the results in each of these streams, we expect that trust in the integrity of postal voting acts as a moderator and influences the impact of distance on an individual's adoption of postal voting. Therefore, the average marginal effect of the distance on the probability to vote will increase with one's level of trust (Hypothesis 3). In other words, those with low levels of trust are expected to be less likely to adopt postal voting, and increasing the distance of the nearest polling station will have a much smaller effect (if any) on their probability to cast a ballot via post, as depicted in Fig. 1. 


\section{Context: Postal Voting in Finland}

Finland constitutes a great case to study the adoption of postal voting among individuals. During the last two decades, Finnish governments have been increasingly inspired to find solutions to include the ever-increasing electorate abroad. Unprecedented change in electoral law was conducted as postal voting for the electorate abroad was adopted in parliamentary elections in 2019. The reasons were similar to those of other countries following the same path-to make voting more convenient for non-resident citizens and thus enhance equality in electoral participation. In fact, before the implementation of postal voting, 35-38\% of non-resident non-voters claimed they would probably vote if the method of voting was more convenient, for instance, if postal or internet voting was possible (Peltoniemi, 2018, pp. 117-121).

The 2019 Finnish parliamentary election was the first opportunity for postal voting to be implemented, and it was straight adopted by a substantive portion-14.1\% — of non-resident voters. Simultaneously, turnout among non-resident voters increased by $2.5 \%$ to $12.6 \%$, which was the all-time high. Because this was the first occasion, and the implementation of postal voting was not marked with any previous anecdotal experiences, this research can examine the real expectations emigrant voters have when they approach and assess postal voting as a possibility for their electoral participation.

Prior to the adoption of postal voting, non-resident Finnish voters were entitled to vote and stand as candidates. External voting was possible at diplomatic missions in addition to in-country voting. This means that even before the implementation of postal voting, non-resident Finns had relatively good standing when it comes to the conditions of electoral rights compared to other European Union member statesthey were eligible to vote and run for office and cast a ballot abroad in polling stations organized by diplomatic missions. Many emigrants of EU member states have more restricted electoral rights or accessibility of voting (for comparison, see Peltoniemi, 2018, pp. 126-129).

This favorable situation results from actions taken by the two collective interest groups for non-resident Finns: Finland Society and Finnish Expatriate Parliament. Both groups actively approached homeland authorities and lobbied in favor of postal voting for nearly two decades before it was implemented. When it came to implementation, the protocol for postal voting was adopted very straightforwardly from the one utilized in Sweden.

\section{Data and Methods}

The data used in this study originate from a survey conducted in 2019 among Finnish citizens residing abroad. The goal was to study the implications of external voting in the most recent parliamentary elections held on 14 April 2019. The survey 
approached a disproportionate stratified random sample ${ }^{2}$ of 10,000 Finnish emigrants entitled to vote. The sample was drawn from the Population Register Center of Finland. Selected individuals were invited to participate via a letter sent by post to their registered physical address. The invitation included a unique code and instructions on how to access the online survey via their own devices. The sample included residents from the 17 largest diasporas (countries with more than 1000 citizens with the right to vote in Finnish elections). In each country, the survey approached 500 persons; the exception was Sweden (i.e., an exceptionally large Finnish diaspora), where the sample consisted of 1500 persons. An additional 500 Finnish non-resident citizens were invited from the rest of the world (i.e., residing in any other country than one of the 17 largest diasporas). ${ }^{3}$

The responses were collected with an online survey questionnaire which covered a wide range of questions related to political attitudes and electoral participation. The questionnaire was available in three languages: in the two official languages of Finland-Finnish and Swedish-as well as in English. The data collection took place between 23 May 2019 and 30 September 2019, starting more than a month after the parliamentary election. Only ten days after we dispatched the invitation letters, the new Finnish government presented its program (see Arter, 2020). Therefore, we do not expect that the development in Finnish politics could have any strong influence over respondents' answers in the survey during the duration of data collection.

Four months may sound like a relatively long data collection period, especially when compared to the surveys collecting data within a single country. However, it is due to logistical reasons: We needed to allow a sufficiently long time for the invitation letter to reach selected participants (which might take up to eight weeks). Then, we needed to wait until all respondents who wanted to participate could find a convenient moment to fill in the questionnaire. Therefore, we monitored the response rate and closed the survey at the end of the month when no additional responses arrived for two consecutive weeks. ${ }^{4}$

The effective response rate was slightly over $20 \%$. Although the response rate may seem rather low in comparison to similar surveys collected among resident citizens, it is largely in line with other surveys collected among citizens abroad. In two previous larger data sets collected from non-resident citizens, the response rate was 20-30\% (Peltoniemi, 2018; University of Gothenburg, 2016). It should be

\footnotetext{
${ }^{2}$ We use the term disproportionate stratified random sample because the invited individuals were randomly selected from the database of all Finnish citizens residing abroad included in the Population Register Center of Finland. In addition, the sample is stratified because we set quotas for the number of invited persons from individual countries (otherwise, we would risk overrepresentation of the most populous diasporas). Finally, the sample is disproportionate because the size of these quotas does not reflect the proportion of Finns living in the countries.

${ }^{3}$ For overview of the diaspora sizes and number of survey participants per country, see Appendix B.

${ }^{4}$ In fact, a four-month long data collection period is not unusual for surveys of emigrant citizens. The Global Swedes Abroad SOM Survey 2014 (University of Gothenburg, 2016) invited 10,000 Swedes residing abroad, and its data collection lasted from 27 September 2014 to 30 January 2015, which constitutes a comparably long period.
} 


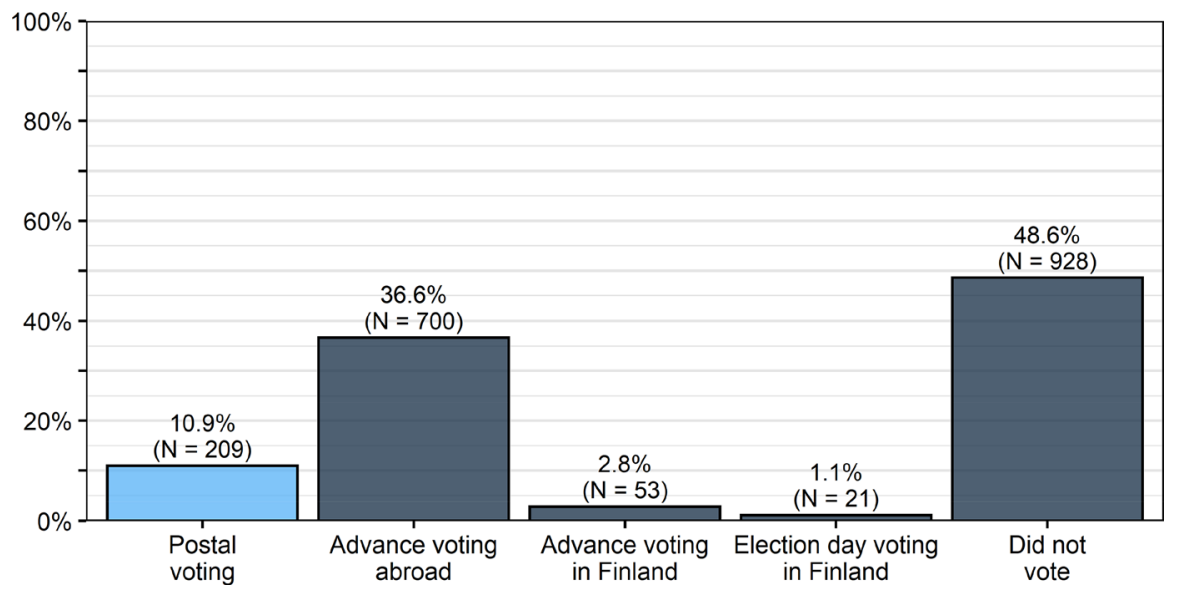

Fig. 2 Adoption of various voting methods among Finnish citizens residing abroad and voting in the 2019 Parliamentary elections. The category "Did not vote" comes from the question "Did you vote in Finnish parliamentary elections in 2019?" Two respondents declared that they voted, but they did not indicate the method of their electoral participation, and 188 respondents did not provide an answer

mentioned that any kind of representative random sample of non-resident citizens is rare (Ahmadov \& Sasse, 2016). The fact that our survey was able to reach Finns living abroad depending on their current country of residence was possible only thanks to the Finnish population register system, which also includes non-resident citizens.

\section{Subset and Variables}

Altogether 2101 respondents participated in our survey, of which 983 indicated a voting method employed in the 2019 Finnish parliamentary elections. Of the respondents, 928 declared that they did not vote. Another 188 respondents skipped the questions, and two participants answered that they voted but did not specify their method of electoral participation. However, due to the missing values of some control variables which enter analysis as potential theoretically relevant confounders, the final number of suitable cases for the analysis decreased from 983 (all respondents who specified their method of electoral participation) to 664 individuals (see Fig. 2). ${ }^{5}$

\footnotetext{
5 This dropout rate might raise concerns about potential introduction of unobserved variation that could bias the findings. To mitigate these concerns, we compare the three samples-(1) Full sample $(n=2101)$, (2) subsample of voters $(n=983)$, and (3) subsample used for models $(n=664)$ in Table A2 in the online appendix. The comparison shows that the compositions of the samples are largely consistent with respect to the three main variables of interest: voting method, distance measure, and degree of trust. The dropout slightly increased the representation of politically interested individuals and those who perceive voting as a civic duty. Nonetheless, the increase is minor, and we do not aim to interpret the results of control variables. Therefore, the dropout gives little reason for concerns with respect to the reliability of the findings.
} 


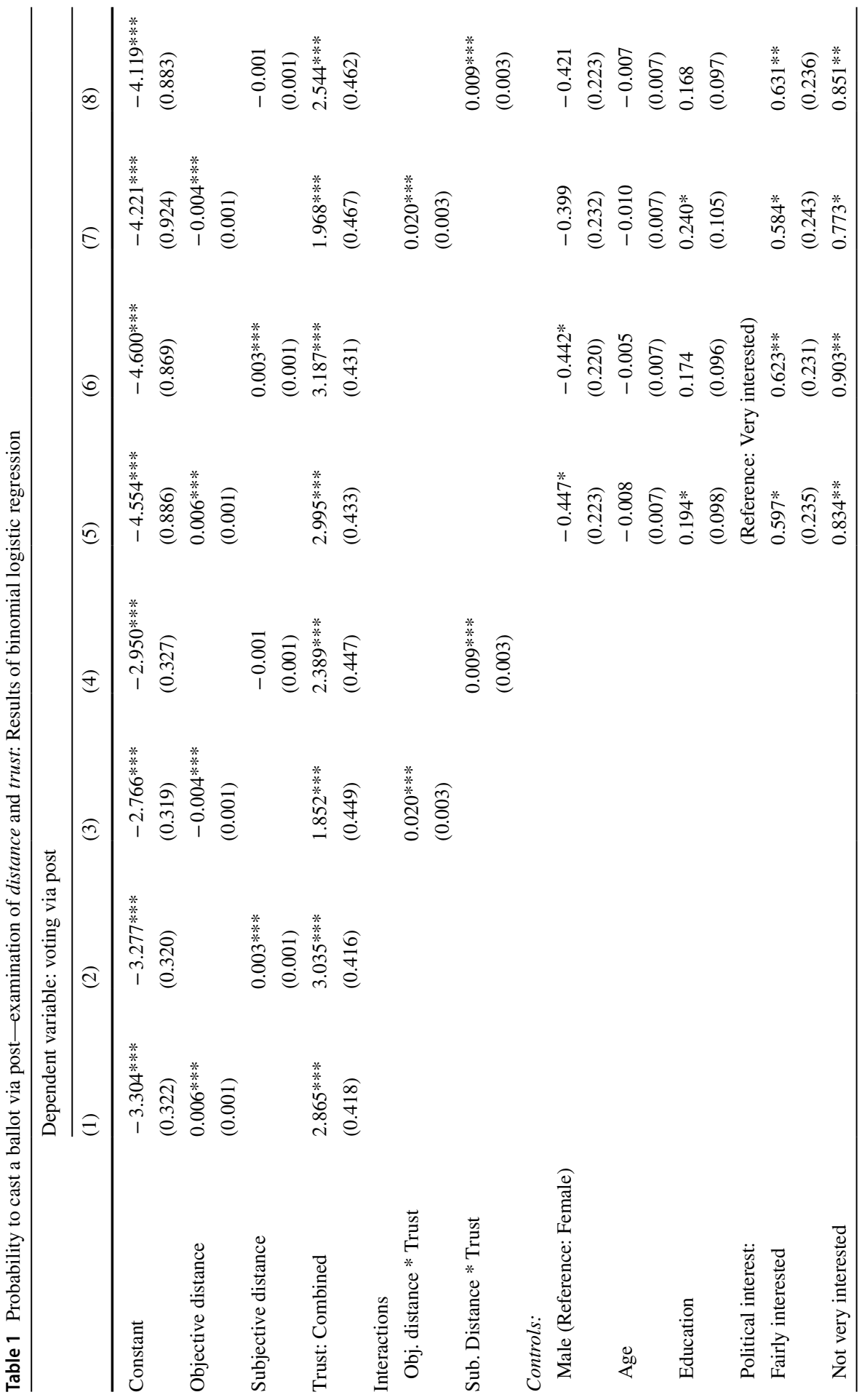




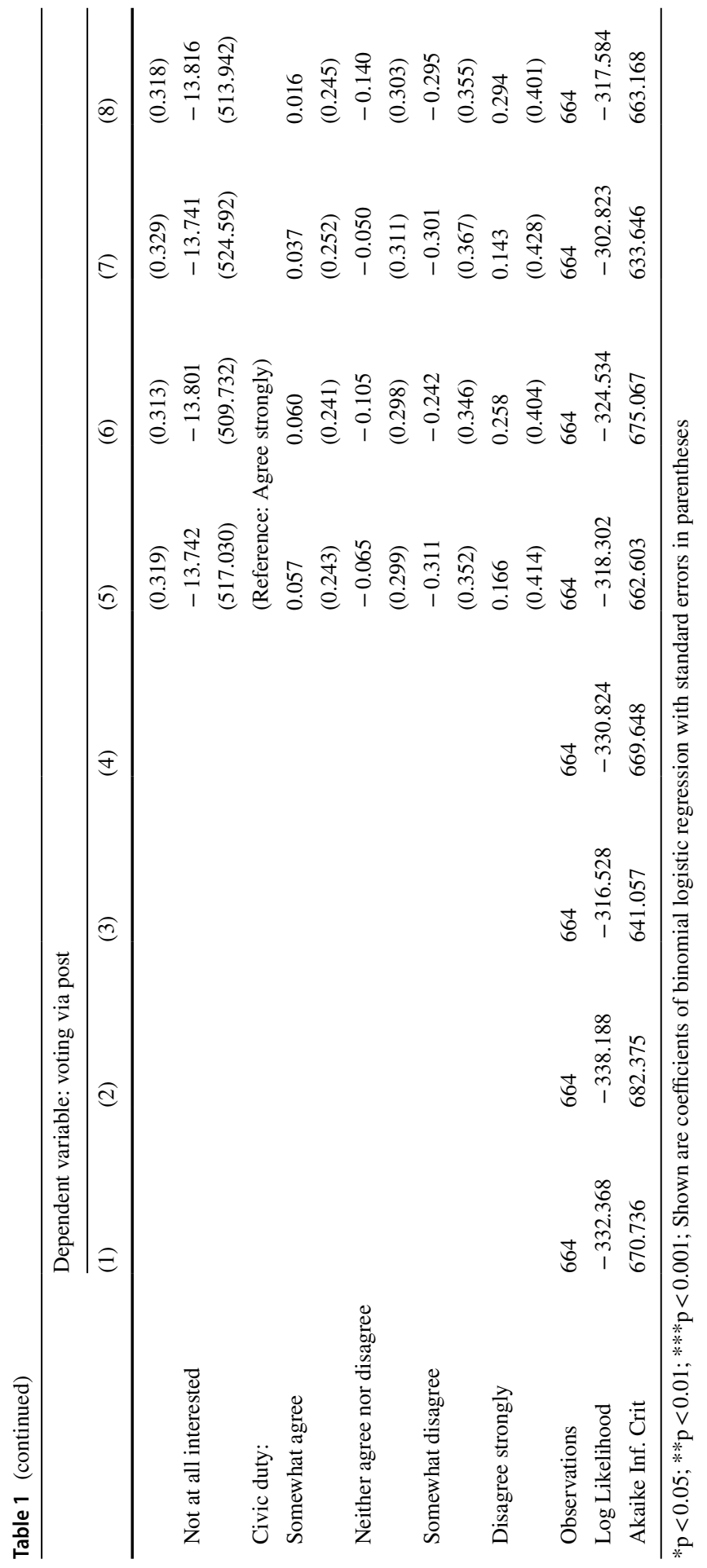


Beginning with the 2019 national elections, the Finnish electoral system offered voters residing in a foreign country four options to cast their electoral ballot. Two methods allow voting while staying abroad: (1) voting via post and (2) advanced voting abroad at one of the Finnish representative offices (e.g., embassy, consulate). The two remaining methods require voters to travel to Finland: (3) advance voting in Finland and (4) voting in Finland on election day. In the conducted survey, respondents who stated that they turned out in the 2019 elections were asked, "How did you vote / which method did you use to cast your vote?" and offered the abovementioned set of four options. Based on their responses, we were able to construct a binary variable postal voter, which was used as a dependent variable in the binomial logistic regression models estimated for this research.

Overall, the survey includes $11 \%$ of respondents who reported using postal voting as their method of electoral participation (see Fig. 2). If we focus only on the subsample of voters $(n=985)$, early adopters of postal voting (given its recent implementation in 2019) already constitute a substantive group of voters among Finnish citizens residing abroad. More than every fifth respondent $(21 \%)$ declared having delivered their ballot via post in the 2019 elections in Finland.

Our theoretical propositions focus on two independent variables: (1) trust in postal voting as a voting method and (2) distance from the polling station (for an overview of variable constructions used in the analysis, see Appendix A).

Trust in postal voting is measured by two survey items introduced with the question, "Do you agree or disagree with the following statements regarding postal voting in Finnish parliamentary elections?" (1) "Postal voting jeopardizes the secrecy of the ballot" and (2) "Postal voting enables electoral fraud." Respondents were offered five options ranging from $1=$ Agree strongly to $5=$ Disagree strongly (see Appendix A for details). These two responses were combined into a single interval ranging from $0=$ Complete distrust to $1=$ Complete trust. Internal consistency of the measure is Cronbach's alpha $=0.85 .^{6}$

Distance from the polling station is measured in two ways: subjective and objective. Subjective (perception of the) distance to the nearest polling stations is based on a numerical response to a write-in question: "What is the distance from where you live to the nearest polling station where you can vote in Finnish elections (approximately, kilometers)?" Objective distance to the polling station represents the length of the route between the respondent's address where the invitation to participate in the survey was delivered and the nearest polling station organized by Finnish administration abroad. These two measures do not have to be identical because individuals might respond with (a) an approximate distance, (b) distance from their work or other place of interest, or (c) distance from the temporary address if they visit Finland during the elections. In addition, (d) Google maps can sometimes approximate the respondent's address (if, e.g., no street number or only zip code is known to

\footnotetext{
${ }^{6}$ The findings of this research hold regardless of the trust measure used in the analysis. Table A1 and Figure A2 in the online appendix demonstrate that the results are very similar even when the survey questions are used separately. Therefore, combining the two survey items into a unitary scale has no influence on the findings.
} 
its database). Despite these potential shortcomings, the Spearman's rank correlation between the two distance measures is high $-\rho=0.84$ (for a visual depiction, see Figure A1 in the online appendix), mitigating reliability concerns related to either of the measures. Since the distribution of both distance measures is right-skewed towards shorter distances, the analysis uses their decimal logarithmic transformation.

Lastly, the analysis controls for a set of basic sociodemographic factors that could potentially confound the results. Control variables include gender and age (in years; calculated from birth year), the latter because older voters may be increasingly hesitant to adopt a newly implemented voting technique. In addition, the models control for education $(1=$ Still in school [comprehensive school, high school, vocational school, etc.], 2 =Elementary school [folke schoole, kansakoulu], $3=$ Comprehensive school, $4=$ Vocational school, $5=$ Gymnasium or abitur, $6=$ Polytechnic school, $7=$ University, $8=$ Licentiate or doctoral degree), because the more educated respondents may better understand the risks related to casting a ballot via post. $^{7}$ Also, Blais and Daoust (2020) demonstrate that explaining one's motivation to turn out needs to take civic duty and political interest into account. Therefore, we included the civic duty as measured by the response to the statement "Finnish citizens residing abroad have a duty to vote in Finland's elections," on a five-point scale ranging from "Agree strongly" to "Disagree strongly." Political interest was measured as "How interested would you say you personally are in [Politics in Finland]?" offering four responses from "Very interested" to "Not at all interested." (For a detailed overview of all variables included in the analysis, see Appendix A.)

One can argue that we should also control for numerous factors acknowledged to influence turnout among individuals. First, as suggested by Dyck and Gimpel (2005), considerations about whether to turn out and which voting method to use constitute two relatively separate processes, even though they may be two subsequent decisions. Therefore, it could be expected that these two choices are driven by two separate sets of factors that may overlap, but only to a certain degree. Of course, the absence of a sufficiently convenient voting method may result in abstention. However, that should exceptionally apply to the 2019 Finnish elections because voters residing abroad had two options: postal voting and voting in person at a diplomatic mission. Second, the turnout literature has found that all the above-mentioned control variables (in some form) play a role in individuals' decisions to turn out (Blais, 2006; Smets \& van Ham, 2013). Therefore, even though our set of controls is specifically deduced to control potential confounders in the adoption of postal voting, it also controls for some relevant correlates of turnout.

\footnotetext{
7 Education enters the models as a numeric data type. Because of the high number of categories and skewed distribution towards high education level (even when the levels are aggregated into, e.g., primary, secondary, and tertiary education), the variable cannot be used as a factor. Thus, this is the only way we can control individuals' education levels.
} 


\section{Estimation Strategy}

The point of departure for our analysis is the two models, 1 and 2, which solely examine the effects of the main variables of interest: distance and trust (see Table 1). The reason for two models is that model 1 includes objective and model 2 includes subjective distance measures. An analogous reason applies to all subsequent pairs of models (i.e., models 3 and 4, models 5 and 6, and models 7 and 8). Then, the specification includes an interaction term between trust and distance (models 3 and 4), which allows inspection of the effect of distance across voters at various levels of the moderator trust.

The same logic is followed in the second set of estimated models (models 5 to 8), which adds an above-discussed set of theoretically relevant control variables. The results are similar, which indicates that the results are robust towards the inclusion of potential confounders.

Due to the challenges related to the interpretation of coefficients in binomial logistic models and interaction terms (included in some specifications), the results are visualized and interpreted with respect to the figures. These figures are based on full model specifications controlling for potential confounders-models 5 to 8 depending on the hypothesis under consideration.

\section{Analysis}

Results of the binomial logistic regression models are presented in Table 1 following the estimation strategy discussed in the previous section. Coefficients for trust indicate that individuals who fully trust the integrity of postal voting are 2 to 3 times more likely to adopt postal voting (depending on the model specification) than are voters who do not trust the technique. When it comes to the distance, coefficients are rather small due to the large range of distances in data. Yet, at the same time, small coefficient sizes suggest that increasing distance will have a larger effect as the distance to the nearest polling station gets longer. When the models do not include interaction terms (i.e., models 1, 2, 5, and 6), the association is positive, and the increasing distance is on average associated with increasing odds that individuals will mail their ballots. However, when the models add interaction terms (i.e., models $3,4,7$, and 8), both subjective and objective trust coefficients become negative, suggesting that this negative effect is characteristic for non-trusting individuals who are unlikely to adopt postal voting despite increasing distances to the nearest polling station. The likelihood to adopt postal voting among other people as their level of trust increases is estimated in interaction term coefficients, which are still positive and larger (compared to the models without the interactions). This indeed indicates that the effect of distance is moderated by individuals' level of trust in postal voting, and we will further examine the differences below.

The above-outlined effects are consistent and roughly comparable across all similar model specifications (when comparing the models with and without interaction terms separately). The same applies when model results are compared with and without control variables. This suggests that the findings are robust, including 

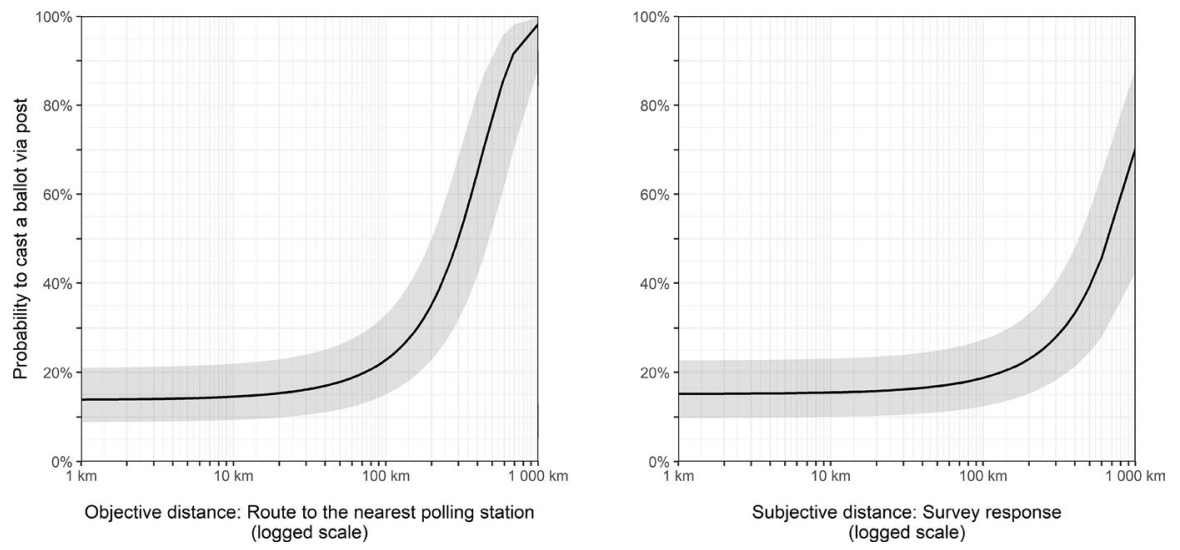

Fig. 3 The marginal effect of an individual's distance from polling station on probability to cast a ballot via post. Estimates from models 5 and 6 in Table 1
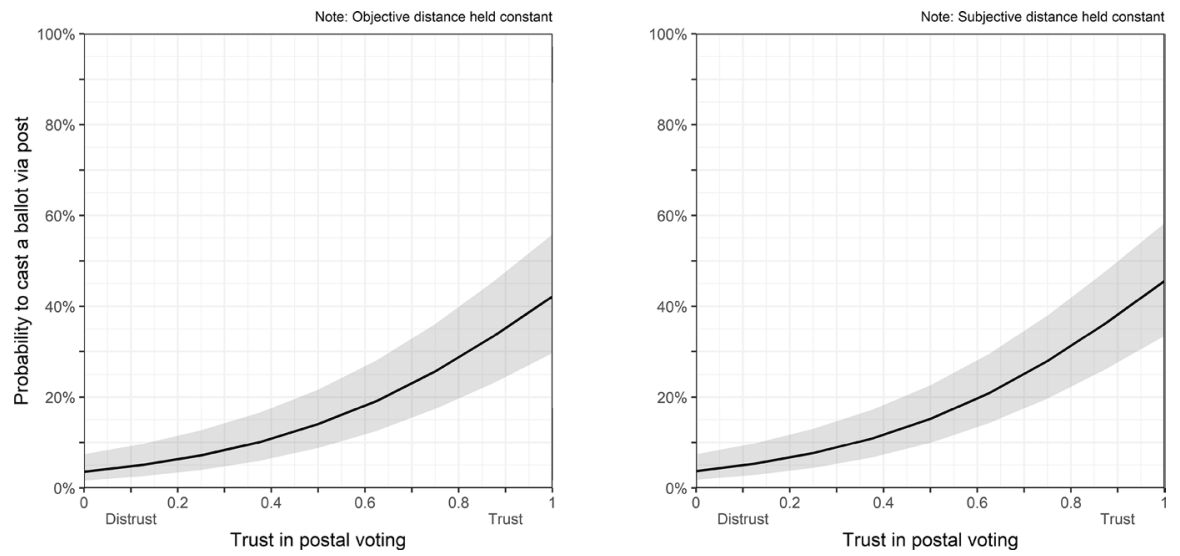

Fig. 4 The marginal effect of trust in postal voting on probability to cast a ballot via post. Estimates from models 5 and 6 in Table 1

robustness towards the inclusion of potential confounders. Even though we will further examine the marginal effects of the relevant variables more in detail, the results already confirm that increasing trust and increasing distance from the nearest polling station are positively associated with the likelihood to adopt postal voting among individuals. Such findings successfully replicate the conclusions reported in the previous literature and provide strong empirical support for hypotheses 1 and 2.

The estimated probability to adopt postal voting along the expanding distance to the nearest polling stations is visualized in Fig. 3 (as a marginal effect of objective distance based on model 5 and a marginal effect of subjective distance based on model 6, both from Table 1). As can be seen, both distance measures yield similar trends; however, they have somewhat different substantive effects. Figure 3 showcases that the objective distance has limited influence on the adoption of postal 

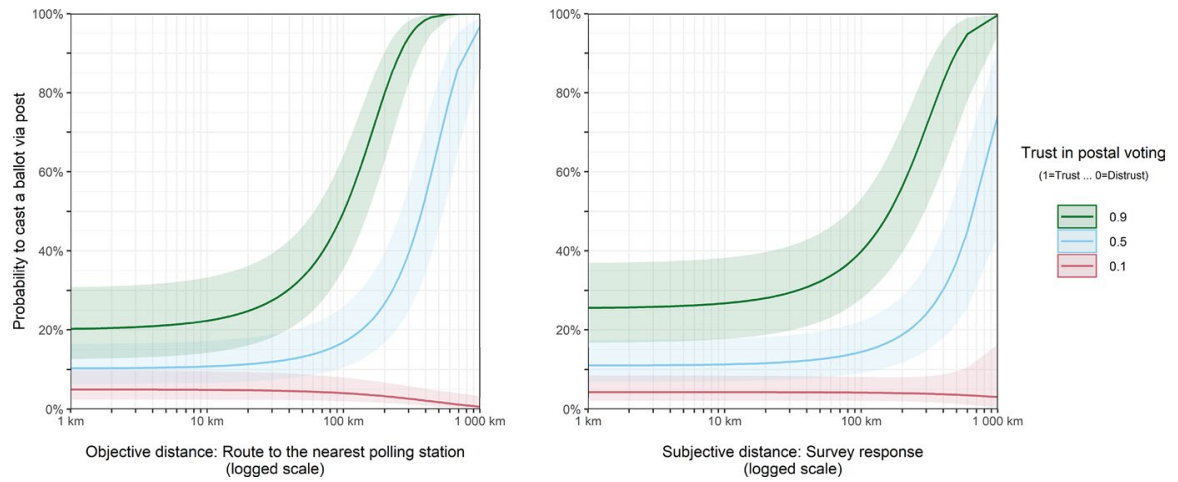

Fig. 5 The moderating effect of trust: Interaction effect between trust and distance on probability to cast a ballot via post. Estimates from Model 8 in Table 1

voting if emigrant voters can reach their closest polling station within roughly $40-50 \mathrm{~km}$. After that, the effect quickly accelerates. Whereas when it comes to the subjective distance, the effect is slightly delayed, and it starts to increase quickly after approximately $100 \mathrm{~km}$. This may be due to the measurement issues mentioned in the methodological section when the operationalization of both distance measures is discussed. Nevertheless, these results demonstrate that distance constitutes an important factor leading individuals to adopt postal voting if they would otherwise need to dedicate substantial resources (i.e., money, time) to vote in person. However, postal voting is not adopted by those for whom the polling station is easily achievable.

With respect to trust in postal voting as a voting technique, the respective coefficients in Table 1 suggest that the odds of casting one's ballot via post also increase along the variable range. The trend is visualized in Fig. 4 (based on models 5 and 6 holding constant the objective and subjective distance, respectively, as well as the set of control variables). The probability to adopt postal voting among Finnish nonresident voters whose aggregated trust score is below 0.4 is around (or below) $10 \%$. The probability increases to between 40 and $45 \%$ as we move towards the highesttrusting individuals; hence, it becomes four times higher along the full range of the trust variable.

A more substantive interpretation is possible if we break down the index into its constitutive values. As described in the methodological section, the measure of trust is composed of two negatively framed statements about postal voting for which respondents were offered a five-point Likert scale ranging from "Agree strongly" to "Disagree strongly" (see Appendix A). Therefore, the respondents who agreed (or strongly agreed) with negative statements about characteristics of postal voting revealed a low likelihood of mailing their ballot (only up to 10\%). As their attitudes move towards positive perception, their estimated probability rapidly increases, which also confirms the findings commonly reported in the literature.

Finally, Fig. 5 presents the moderating effect of trust on the link between distance and adoption of postal voting among individuals (based on full model specification 
including interaction terms in models 7 and 8). The figure visualizes three levels of trust: low, medium, and high, represented by the values $0.1,0.5$, and 0.9 of the trust index, respectively. We refrain from using values 0 and 1 in order to not visualize extremes.

Estimated probabilities reveal that short distance to the nearest polling station has a limited impact on postal voting among the three groups of non-resident voters differentiated by their level of trust. Indeed, high-trusting individuals are significantly more likely to mail in their ballots compared to emigrant voters with low trust (approximately $20-25 \%$ vs. 5\% probability, respectively). Nevertheless, the distance has minimal impact if the polling station is within the range of up to ten kilometers. However, the group trends begin to differ beyond this point. While the low-trusting individuals remain indifferent and their probability to cast a ballot via post stays low regardless of the distance (or even slightly decreases), medium-trusting non-resident voters begin to increasingly utilize postal voting when the nearest polling station is further than $100 \mathrm{~km}$ away. The trend grows considerably faster among high-trusting individuals who increasingly mail their ballots to electoral authorities when the nearest polling station is ten or $30 \mathrm{~km}$ away (depending on subjective or objective distance, respectively), see Fig. 5. These findings provide straightforward and strong empirical support for the notion that trust acts as a moderator between distance and probability to adopt postal voting, as expected in hypothesis 3 , which is confirmed.

\section{Conclusions}

The availability of postal voting for citizens temporarily or permanently residing abroad imposes a dilemma. On the one hand, postal voting is a convenient way to deal with the long distance to the nearest polling station, which can become quite costly to overcome, especially if the diplomatic mission organizing voting is located in a distant city or neighboring country. However, on the other hand, postal voting requires a ballot to pass a long way almost completely unsupervised - from the moment the envelope is dispatched at a local postal office or a residential mailbox until its delivery to the ballot box by national authorities administering election in the country of origin. Moreover, the procedure needs to be completed before the election day. This requires a substantial amount of trust in the integrity of the procedure among voters who must believe that their vote will not become compromised or delayed somewhere along the way.

The literature has examined these two factors-distance and trust-separately, and both have been found to influence voters' decisions to adopt postal voting as the means of their electoral participation. As was also confirmed in this research, increasing distance and increasing trust in the integrity of postal voting are both positively related to the likelihood that (emigrant) voters will cast their ballots via post. However, the interaction of these two factors has not yet been studied. Herein lies the original contribution of this study-it bridges the two streams of the literature and examines the interaction of the two factors: How trust in the postal voting moderates the impact of distance on the willingness to cast one's ballot via post. 
The results are based on the analysis of 664 complete responses provided by Finns residing abroad in an original survey conducted in cooperation with the Population Register Center of Finland shortly after the first implementation of postal voting in the Finnish 2019 Parliamentary elections. The findings confirmed our theoretical expectation that trust acts as a moderator and influences the impact of distance on one's probability of mailing their electoral ballot. High-trusting individuals, compared to their low-trusting peers, are roughly four times more likely to adopt postal voting when the nearest polling station is less than ten kilometers away, although the distance itself has only limited influence up to this point. However, as the distance increases, so do the differences across the groups, depending on their level of trust in the integrity of postal voting. Low-trusting non-resident voters remain largely indifferent regardless of the distance to the nearest polling station, whereas the effect is considerably stronger among medium- and high-trusting individuals. The probability that voters with medium trust will adopt postal voting starts to rapidly increase when the nearest polling station is more than $100 \mathrm{~km}$ away, while the non-resident citizens most enthusiastic about postal voting tend to increasingly mail in their ballots when the distance to the nearest polling station is ten to $30 \mathrm{~km}$. The stark differences across these groups provide empirical evidence that the degree of doubt about the integrity of postal voting acts as a moderator and influences the impact that distance might have on one's decision of which method to use for their electoral participation.

These results not only bridge the research of voting behavior and political geography but they also have important practical implications for the implementation of postal voting. In order to work, the postal voting procedure must strengthen supervisory mechanisms aiming to universally increase trust in its integrity. If election authorities do not address concerns of low-trusting individuals, their intentions to universally enable electoral participation of citizens residing far away from the polling stations cannot be fully successful. This is because postal voting in its current form does not provide a satisfactory solution for citizens who feel uneasy about the lack of control over their ballot during its long trip to the ballot box, regardless of the validity of their concerns. Therefore, future research should examine best practices and develop new solutions to improve voter trust in the integrity of external voting. In addition, it must be admitted that our results are based on a survey conducted only among Finnish citizens residing abroad. As pointed out in the theoretical section, the adoption of voting techniques among emigrant electorates seems to follow various trends. Therefore, future research should also aim to replicate our results in different contexts. 


\section{Appendix A Variables used in the analysis}

\begin{tabular}{|c|c|c|c|}
\hline \multicolumn{4}{|c|}{ Dependent variable } \\
\hline Var. name & Survey question & Provided answers & $\begin{array}{l}\text { Values } \\
\text { used in } \\
\text { analysis }\end{array}$ \\
\hline \multirow[t]{4}{*}{ Postal voter } & \multirow{4}{*}{$\begin{array}{l}\text { How did you vote/which method did you } \\
\text { use to cast your vote? }\end{array}$} & 1 Postal voting & 1 \\
\hline & & 2 Advance voting abroad & 0 \\
\hline & & 3 Advance voting in Finland & 0 \\
\hline & & 4 Election day voting in Finland & 0 \\
\hline
\end{tabular}

\begin{tabular}{|c|c|c|c|c|}
\hline \multicolumn{5}{|l|}{ Independent variables } \\
\hline Var. name & $\begin{array}{l}\text { Definition/Survey } \\
\text { question }\end{array}$ & \multicolumn{2}{|c|}{ Provided answers } & $\begin{array}{l}\text { Values used in } \\
\text { analysis }\end{array}$ \\
\hline Distance: Subjective & $\begin{array}{l}\text { What is the distance } \\
\text { from where you } \\
\text { live to the nearest } \\
\text { polling station } \\
\text { where you can vote } \\
\text { in Finnish elections } \\
\text { (approximately, } \\
\text { kilometers)? }\end{array}$ & \multicolumn{2}{|c|}{ [write-in response] } & Numerical value \\
\hline Distance: Objective & $\begin{array}{l}\text { Calculated distance } \\
\text { between the } \\
\text { respondent's } \\
\text { address (where } \\
\text { invitation to partic- } \\
\text { ipate in the survey } \\
\text { was delivered) and } \\
\text { the nearest polling } \\
\text { station outside of } \\
\text { Finland }\end{array}$ & N/A & & Numerical value \\
\hline \multirow{5}{*}{$\begin{array}{l}\text { Trust in postal vot- } \\
\text { ing: Jeopardizes } \\
\text { the ballot secrecy }\end{array}$} & \multirow{5}{*}{$\begin{array}{l}\text { Do you agree or } \\
\text { disagree with the } \\
\text { following state- } \\
\text { ment regarding } \\
\text { postal voting in } \\
\text { Finnish parliamen- } \\
\text { tary elections? } \\
\text {-Postal voting jeop- } \\
\text { ardizes the secrecy } \\
\text { of the ballot }\end{array}$} & 1 & Agree strongly & 1 \\
\hline & & 2 & Somewhat agree & 2 \\
\hline & & 3 & $\begin{array}{l}\text { Neither agree nor } \\
\text { disagree }\end{array}$ & 3 \\
\hline & & 4 & Somewhat disagree & 4 \\
\hline & & 5 & Disagree strongly & 5 \\
\hline \multirow{5}{*}{$\begin{array}{l}\text { Trust in postal } \\
\text { voting: Enables } \\
\text { electoral fraud }\end{array}$} & \multirow{5}{*}{$\begin{array}{l}\text { Do you agree or } \\
\text { disagree with the } \\
\text { following state- } \\
\text { ment regarding } \\
\text { postal voting in } \\
\text { Finnish parliamen- } \\
\text { tary elections? } \\
\text {-Postal voting ena- } \\
\text { bles electoral fraud }\end{array}$} & 1 & Agree strongly & 1 \\
\hline & & 2 & Somewhat agree & 2 \\
\hline & & 3 & $\begin{array}{l}\text { Neither agree nor } \\
\text { disagree }\end{array}$ & 3 \\
\hline & & 4 & Somewhat disagree & 4 \\
\hline & & 5 & Disagree strongly & 5 \\
\hline
\end{tabular}


Independent variables

\begin{tabular}{|c|c|c|c|c|}
\hline Var. name & $\begin{array}{l}\text { Definition/Survey } \\
\text { question }\end{array}$ & Pro & inswers & $\begin{array}{l}\text { Values used in } \\
\text { analysis }\end{array}$ \\
\hline \multirow{6}{*}{$\begin{array}{l}\text { Trust in postal vot- } \\
\text { ing: Combined } \\
\text { score }\end{array}$} & \multirow{6}{*}{$\begin{array}{l}\text { Combined score: } \\
\text { Do you agree or } \\
\text { disagree with the } \\
\text { following state- } \\
\text { ments regarding } \\
\text { postal voting in } \\
\text { Finnish parliamen- } \\
\text { tary elections? } \\
\text {-Postal voting jeop- } \\
\text { ardizes the secrecy } \\
\text { of the ballot } \\
\text {-Postal voting ena- } \\
\text { bles electoral fraud }\end{array}$} & & & Score: \\
\hline & & 1 & Agree strongly & $0=$ Total distrust \\
\hline & & 2 & Somewhat agree & \\
\hline & & 3 & $\begin{array}{l}\text { Neither agree nor } \\
\text { disagree }\end{array}$ & $\ldots$ \\
\hline & & 4 & Somewhat disagree & \\
\hline & & 5 & Disagree strongly & $1=$ Total trust \\
\hline
\end{tabular}

\begin{tabular}{|c|c|c|c|c|}
\hline \multicolumn{5}{|l|}{ Control variables } \\
\hline Var. name & Survey question & Pr & inswers & Values used in analysis \\
\hline \multirow[t]{3}{*}{ Gender } & \multirow[t]{3}{*}{ Do you identify as... } & & Male & 1 \\
\hline & & & Female & 0 (Reference group) \\
\hline & & & Other gender & - \\
\hline Age & $\begin{array}{l}\text { What is your year of } \\
\text { birth? }\end{array}$ & & esponse] & $\begin{array}{l}\text { Calculated age (i.e., } \\
2019 \text { minus year of } \\
\text { birth) }\end{array}$ \\
\hline \multirow[t]{8}{*}{ Education } & \multirow[t]{8}{*}{$\begin{array}{l}\text { What is your highest } \\
\text { level of education or } \\
\text { degree? }\end{array}$} & 1 & $\begin{array}{l}\text { Still in school (compre- } \\
\text { hensive school, high } \\
\text { school, vocational } \\
\text { school, etc.) }\end{array}$ & 1 \\
\hline & & 2 & $\begin{array}{l}\text { Elementary school } \\
\text { (folke schoole, kansa- } \\
\text { koulu) }\end{array}$ & 2 \\
\hline & & 3 & Comprehensive school & 3 \\
\hline & & 4 & Vocational school & 4 \\
\hline & & 5 & Gymnasium or abitur & 5 \\
\hline & & 6 & Polytechnic school & 6 \\
\hline & & 7 & University & 7 \\
\hline & & 8 & $\begin{array}{l}\text { Licentiate or doctoral } \\
\text { degree }\end{array}$ & 8 \\
\hline \multirow[t]{5}{*}{ Political interest } & \multirow{5}{*}{$\begin{array}{l}\text { How interested would } \\
\text { you say you person- } \\
\text { ally are in politics? } \\
\text { - Politics in Finland }\end{array}$} & 1 & Very interested & 1 \\
\hline & & 2 & Fairly interested & 2 \\
\hline & & 3 & Not very interested & 3 \\
\hline & & 4 & Not at all interested & 4 \\
\hline & & 5 & Can't choose & - \\
\hline
\end{tabular}


Control variables

\begin{tabular}{lllll}
\hline Var. name & Survey question & \multicolumn{2}{l}{ Provided answers } & Values used in analysis \\
\hline Civic duty & How much do you & 1 & Agree strongly & 1 \\
& $\begin{array}{l}\text { agree or disagree with } \\
\text { the following state- }\end{array}$ & 2 & Somewhat agree & 2 \\
& ment? & 3 & Neither agree nor & 3 \\
& $\begin{array}{l}\text {-Finnish citizens } \\
\text { residing abroad have } \\
\text { a duty to vote in }\end{array}$ & 4 & Somewhat disagree & 4 \\
& Finland's elections & 5 & Disagree strongly & 5 \\
\hline
\end{tabular}

\section{Appendix B Composition of the sample}

See Table 2 and Fig. 6.

Table 2 Comparison of the Finnish diasporas abroad, group sizes of invited Finnish non-resident citizens, and number of survey participants per country

\begin{tabular}{llll}
\hline Country of residence & $\begin{array}{l}\text { Total number of eligi- } \\
\text { ble voters }\end{array}$ & $\begin{array}{l}\text { Number of invited Finnish non- } \\
\text { resident citizens }\end{array}$ & $\begin{array}{l}\text { Number of } \\
\text { survey partici- } \\
\text { pants }\end{array}$ \\
\hline Sweden & 109,585 & 1500 & 213 \\
USA & 20,841 & 500 & 91 \\
Germany & 15,848 & 500 & 142 \\
United Kingdom & 14,654 & 500 & 107 \\
Canada & 12,483 & 500 & 116 \\
Australia & 8338 & 500 & 86 \\
Switzerland & 7323 & 500 & 127 \\
Norway & 7044 & 500 & 90 \\
Spain & 6134 & 500 & 90 \\
France & 3979 & 500 & 115 \\
Denmark & 3382 & 500 & 125 \\
Netherlands & 2759 & 500 & 128 \\
Italy & 2745 & 500 & 114 \\
Estonia & 2036 & 500 & 83 \\
Belgium & 1867 & 500 & 162 \\
Austria & 1461 & 500 & 129 \\
Israel & 1081 & 500 & 74 \\
Other country $(<1000$ & 33,014 & 500 & 106 \\
eligible voters $)$ & & & $2098^{\mathrm{b}}$ \\
Total & 254,574 & 10,000 & \\
\hline
\end{tabular}

${ }^{a}$ Eligible voters in Finnish national elections include adult Finnish citizens

${ }^{\mathrm{b}}$ The remaining three respondents (to reach the total of 2101 participants) consist of those individuals who returned their questionnaire in a paper form (anonymously) and did not provide information about their current country of residency 


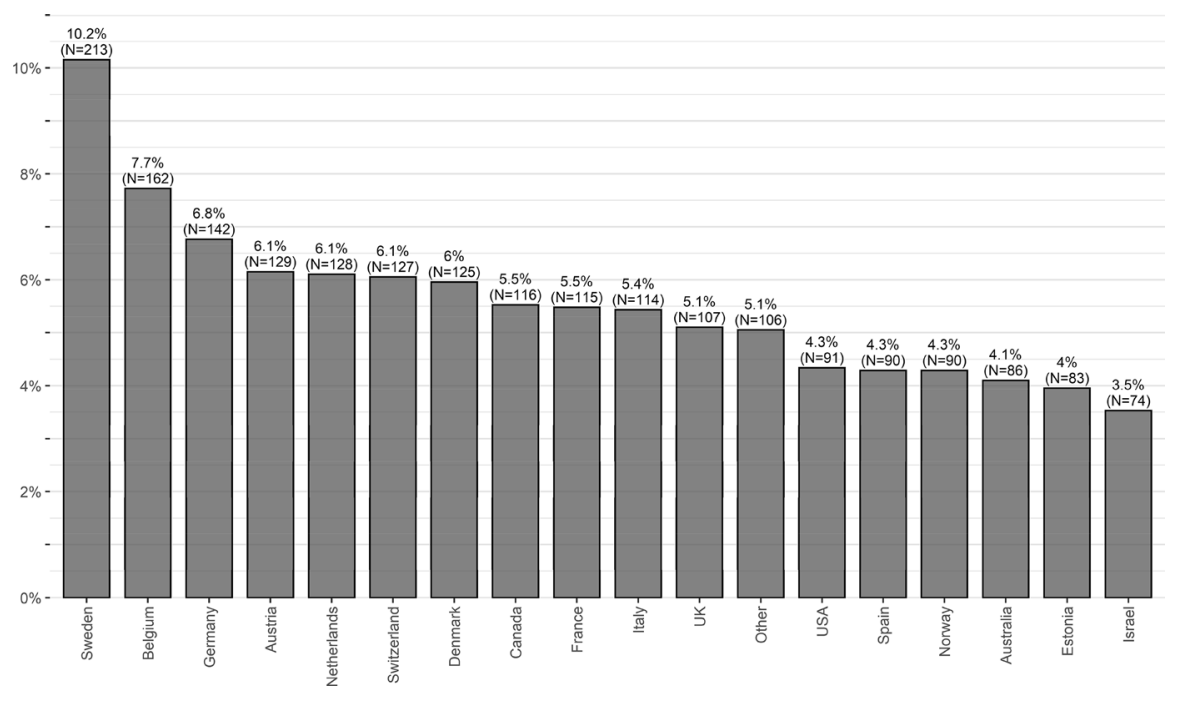

Fig. 6 Comparison of Finnish emigrant survey participants across countries

Supplementary Information The online version contains supplementary material available at https://doi. org/10.1007/s11109-021-09709-7.

Acknowledgements The authors are thankful to Marjukka Weide, Hanna Wass, Staffan Himmelroos, and Philipp Lutscher for assistance with the survey and helpful advice. Also, the manuscript was significantly improved during the peer-review process, which would not be possible without invaluable and constructive suggestions made by anonymous reviewers and the handling editor-in-chief. The authors would like to gratefully acknowledge the funding provided by the Finnish Cultural Foundation (Suomen Kulttuurirahasto), the Society of Swedish Literature in Finland (Svenska Litteratursällskapet i Finland), and the Strategic Research Council of the Academy of Finland (Grant No 312710).

Funding Open access funding provided by University of Oslo (incl Oslo University Hospital).

Open Access This article is licensed under a Creative Commons Attribution 4.0 International License, which permits use, sharing, adaptation, distribution and reproduction in any medium or format, as long as you give appropriate credit to the original author(s) and the source, provide a link to the Creative Commons licence, and indicate if changes were made. The images or other third party material in this article are included in the article's Creative Commons licence, unless indicated otherwise in a credit line to the material. If material is not included in the article's Creative Commons licence and your intended use is not permitted by statutory regulation or exceeds the permitted use, you will need to obtain permission directly from the copyright holder. To view a copy of this licence, visit http://creativecommons.org/licen ses/by/4.0/.

\section{References}

Ahmadov, A. K., \& Sasse, G. (2016). A voice despite exit: The role of assimilation, emigrant networks, and destination in emigrants' transnational political engagement. Comparative Political Studies, 49(1), 78-114. https://doi.org/10.1177/0010414015600468

Arter, D. (2020). When a pariah party exploits its demonised status: The 2019 Finnish general election. West European Politics, 43(1), 260-273. https://doi.org/10.1080/01402382.2019.1635799 
Beckman, L. (2012). Is residence special? Democracy in the age of migration and human mobility. In L. Beckman \& E. Erman (Eds.), Territories of citizenship. (pp. 18-39). Palgrave Macmillan.

Beckman, L. (2014). Democracy and the right to exclusion. Res Publica, 20(4), 395-411. https://doi.org/ $10.1007 / \mathrm{s} 11158-014-9253-\mathrm{y}$

Berinsky, A. J. (2005). The perverse consequences of electoral reform in the United States. American Politics Research, 33(4), 471-491. https://doi.org/10.1177/1532673X04269419

Berinsky, A. J., Burns, N., \& Traugott, M. W. (2001). Who votes by mail?: A dynamic model of the individual-level consequences of voting-by-mail systems. Public Opinion Quarterly, 65(2), 178-197. https://doi.org/10.1086/322196

Bhatti, Y. (2012). Distance and voting: Evidence from Danish Municipalities. Scandinavian Political Studies, 35(2), 141-158. https://doi.org/10.1111/j.1467-9477.2011.00283.x

Birch, S., \& Watt, B. (2004). Remote electronic voting: Free, fair and secret? The Political Quarterly, 75(1), 60-72. https://doi.org/10.1111/j.1467-923X.2004.00572.x

Blais, A. (2006). What affects voter turnout? Annual Review of Political Science, 9(1), 111-125. https:// doi.org/10.1146/annurev.polisci.9.070204.105121

Blais, A., \& Daoust, J.-F. (2020). The motivation to vote: Explaining electoral participation. UBC Press.

Blais, A., Daoust, J. F., Dassonneville, R., \& Péloquin-Skulski, G. (2019). What is the cost of voting? Electoral Studies, 59, 145-157. https://doi.org/10.1016/j.electstud.2019.02.011

Brady, H. E., \& McNulty, J. E. (2011). Turning out to vote: The costs of finding and getting to the polling place. American Political Science Review, 105(1), 115-134. https://doi.org/10.1017/S000305541 0000596

Braun, N., \& Gratschew, M. (2007). Introduction. Voting from Abroad: The International IDEA Handbook. (pp. 1-10). International IDEA.

Dyck, J. J., \& Gimpel, J. G. (2005). Distance, turnout, and the convenience of voting. Social Science Quarterly, 86(3), 531-548. https://doi.org/10.1111/j.0038-4941.2005.00316.x

Foley, E. B. (2020, April 7). Why vote-by-mail could be a legal nightmare in november. Politico. Retrieved from https://www.politico.com/news/magazine/2020/04/07/danger-moving-vote-by-mail-168602

Giammo, J. D., \& Brox, B. J. (2010). Reducing the costs of participation: Are states getting a return on early voting? Political Research Quarterly, 63(2), 295-303. https://doi.org/10.1177/1065912908 327605

Gimpel, J. G., \& Schuknecht, J. E. (2003). Political participation and the accessibility of the ballot box. Political Geography, 22(5), 471-488. https://doi.org/10.1016/S0962-6298(03)00029-5

Gronke, P., Galanes-Rosenbaum, E., Miller, P. A., \& Toffey, D. (2008). Convenience voting. Annual Review of Political Science, 11(1), 437-455. https://doi.org/10.1146/annurev.polisci.11.053006. 190912

Gronke, P., \& Miller, P. (2012). Voting by mail and turnout in Oregon: Revisiting Southwell and Burchett. American Politics Research, 40(6), 976-997. https://doi.org/10.1177/1532673X12457809

Haspel, M., \& Knotts, H. G. (2005). Location, location, location: Precinct placement and the costs of voting. Journal of Politics, 67(2), 560-573. https://doi.org/10.1111/j.1468-2508.2005.00329.x

Hodler, R., Luechinger, S., \& Stutzer, A. (2015). The effects of voting costs on the democratic process and public finances. American Economic Journal: Economic Policy, 7(1), 141-171

Honohan, I. (2011). Should Irish emigrants have votes? External voting in Ireland. Irish Political Studies, 26(4), 545-561. https://doi.org/10.1080/07907184.2011.619749

Karp, J. A., \& Banducci, S. A. (2000). Going postal: How all-mail elections influence turnout. Political Behavior, 22(3), 223-239. https://doi.org/10.1023/A:1026662130163

López-Guerra, C. (2005). Should expatriates vote?*. Journal of Political Philosophy, 13(2), $216-234$. https://doi.org/10.1111/j.1467-9760.2005.00221.x

Luechinger, S., Rosinger, M., \& Stutzer, A. (2007). The impact of postal voting on participation: Evidence for Switzerland. Swiss Political Science Review, 13(2), 167-202. https://doi.org/10.1002/j. 1662-6370.2007.tb00075.x

Mawrey, R. (2010). Easy voting means fraudulent voting. Quadrant Online. Retrieved from https://quadr ant.org.au/magazine/2010/04/easy-voting-means-fraudulent-voting/

Neeley, G. W., \& Richardson, L. E. (2001). Who is early voting? An individual level examination. Social Science Journal, 38(3), 381-392. https://doi.org/10.1016/S0362-3319(01)00135-5

Olsen, K. A., \& Nordhaug, H. F. (2012). Internet elections. Communications of the ACM, 55(8), 36-38. https://doi.org/10.1145/2240236.2240251

Peltoniemi, J. (2016a). Overseas Voters and representational deficit: Regional representation challenged by emigration. Representation, 52(4), 295-309. https://doi.org/10.1080/00344893.2017.1300602 
Peltoniemi, J. (2016b). Distance as a cost of cross-border voting. Research on Finnish Society, 9, 15-27

Peltoniemi, J. (2018). On the borderlines of voting: Finnish emigrants' transnational identities and political participation (Acta Unive.). Tampere University Press.

Puiggali, J., \& Morales-Rocha, V. (2007). Remote voting schemes: A comparative analysis. E-Voting and Identity. (pp. 16-28). Springer.

Qvortrup, M. (2005). First past the postman: Voting by mail in comparative perspective. The Political Quarterly, 76(3), 414-419. https://doi.org/10.1111/j.1467-923X.2005.00700.x

Smets, K., \& van Ham, C. (2013). The embarrassment of riches? A meta-analysis of individual-level research on voter turnout. Electoral Studies, 32(2), 344-359. https://doi.org/10.1016/j.electstud. 2012.12.006

Smith, R. C. (2003). Diasporic memberships in historical perspective: Comparative insights from the Mexican, Italian and Polish Cases. International Migration Review, 37(3), 724-759. https://doi.org/ 10.1111/j.1747-7379.2003.tb00156.x

Song, S. (2012). The boundary problem in democratic theory: Why the demos should be bounded by the state. International Theory, 4(1), 39-68. https://doi.org/10.1017/S1752971911000248

Southwell, P. L. (2010). Voting behavior in vote-by-mail elections. Analyses of Social Issues and Public Policy, 10(1), 106-115. https://doi.org/10.1111/j.1530-2415.2010.01218.x

Southwell, P. L., \& Burchett, J. (1997). Survey of vote-by-mail senate election in the State of Oregon. PS: Political Science and Politics, 30(1), 53-57. https://doi.org/10.2307/420670

Southwell, P. L., \& Burchett, J. (2000). Does changing the rules change the players? The effect of all-mail elections on the composition of the electorate. Social Science Quarterly, 81(3), 837-845

Stewart, C., III. (2010). Losing votes by mail. New York University Journal of Legislation and Public Policy, 13(3), 573-602

Tokaji, D. P., \& Colker, R. (2007). Absentee voting by people with disabilities: Promoting access and integrity. McGeorge Law Review, 38(4), 1015-1064

University of Gothenburg, S. I. (2016). The Global Swedes Abroad SOM Survey 2014. Version 1.0. Gothenburg: Swedish National Data Service

Wass, H., Mattila, M., Rapeli, L., \& Söderlund, P. (2017). Voting while ailing? The effect of voter facilitation instruments on health-related differences in turnout. Journal of Elections, Public Opinion and Parties, 27(4), 503-522. https://doi.org/10.1080/17457289.2017.1280500

Publisher's Note Springer Nature remains neutral with regard to jurisdictional claims in published maps and institutional affiliations. 